

\section{Utlising a Maclntyrean approach to understand how social enterprise may contribute to wellbeing}

\section{Abstract}

Purpose: The aim of this paper is to demonstrate the potential fruitfulness of the theory of Alasdair Maclntyre for understanding how Social Enterprises may facilitate wellbeing, utilising empirical evidence from doctoral research to illustrate this.

Design/methodology/approach: This paper is based on findings from research conducted at a mental health training and employment organisation which utilised gardening as rehabilitative tool. Participant observation and semi-structured interviews with staff, volunteers and service users were used to generate the data, a Maclntyrean lens used to analyse the data, and some suggestions are made as to why social enterprises may be particularly suited to such an approach.

Findings: Practitioners encouraged the seeking of 'internal goods' or 'goods of excellence' within practices, as it was this which was understood to facilitate wellbeing. Service users shared in this view, perceiving their time at the case site, primarily as 'work', and choosing to engage with the service out of a desire to meaningfully contribute to this mental health community.

Research limitations/implications: This research is small-scale and lacks generalisability. The lack of comparison with other organisational forms utilising the same practice is also a limitation.

Originality/value: This theory offers an alternative lens for considering how social enterprises might contribute to wellbeing. The data presented here also complements the growing body of research literature on Work Integration Social Enterprises (WISEs), considering some of the wider wellbeing benefits beyond work integration, which thus far has received limited empirical attention.

Keywords: social enterprise, ethnography, wellbeing, Maclntyrean approach 


\section{Introduction}

Successive UK governments have sought to harness third sector organisations, including social enterprises, in the provision of services due to their perceived capacity to address social problems, and provide more responsive individually-tailored services which can foster the capacity of individuals to lead more independent and fulfilled lives (SEU, 2006; OTS, 2006; Haugh and Kiston, 2007; Cabinet Office 2010). Social enterprises differ from traditional voluntary organisations in that they utilise their trading activity to generate income, reinvesting this income to further their social mission (DTI, 2002). Social enterprises have been positioned as having a key role to play in the reform of healthcare services. For example, they have been viewed as a potential mechanism to enhance the involvement of the public and patients in the design and delivery of services, and also as a means to engage disadvantaged groups who are unlikely to engage with traditional services. These qualities are thought to enable them to contribute to wider social outcomes and the promotion of social inclusion (DH, 2006; 2010)

Within the policy literature in particular, social enterprises have been imbued with the power to address the inadequacies of state and market provision (Macmillan, 2013). However, rather than try to assess the truth of such claims by adding further to the evidence on outcomes, this paper focuses on the practices which are adopted to realise them. Whilst measuring and capturing outcomes is an important endeavour for evidencing impact, it obfuscates how participation in social enterprise practices may be of value in and of itself.

This paper therefore presents an alternative theoretical lens to understand how social enterprises may contribute to wellbeing. Adopting a Maclntyrean approach, it explores how members of the organisation understood their participation in the practice of gardening as promoting a sense of wellbeing. It frames social enterprises in the Maclntyrean sense, as practice-based institutions, whereby, social enterprises, through their commitment to particular social ends, and balancing of hybrid logics (Defourny and Nyssens, 2006), offer vulnerable individuals the opportunity to participate in practices, and in doing so, can provide a fertile environment for seeking excellence within those practices, consequently fostering wellbeing (Maclntyre, 1999; 2007). By illustrating the application of this theory to 
a mental health work-integration organisation, this paper will demonstrate how this theoretical approach may particularly suited for the examination of social enterprise. It therefore adds to the existing theoretical knowledge-base on social enterprises as facilitators of wellbeing, and offers some practical insights into how such a framework can by operationalised.

\section{Background}

Roy et al's (2014a) systematic review of the research evidence identified the possible public health and wellbeing assets and outcomes that may be accrued through social enterprise, and the mechanisms through which they may be realised. Whilst the review showed that some of these outcomes (i.e. social capital, trust, opportunity) may be associated with more traditional voluntary organisations, the business element of social enterprises means that their capacity to generate health and wellbeing is likely to extend further than that of traditional voluntary organisations, in that they can also facilitate local economic development (Roy et al 2013; Roy et al, 2014a). As a consequence, they may also function to address the inequality known to underpin poor health and wellbeing outcomes (Wilkinson and Marmot, 2003; Marmot et al, 2008).

With respect to work integration social enterprises (WISEs) in particular, there is evidence to suggest participation in WISEs impacts positively on volunteers' mental health and selfesteem, providing opportunities for individuals to develop social networks and to build confidence, skills and social capital (Ferguson and Islam, 2008; Ho and Chan, 2010; Williams et al 2010; Teasdale; 2010; Bertotti et al, 2012; Macaulay et al 2018). These have been shown to influence individual and community health and wellbeing. However, given the heterogeneity of social enterprises, the outcomes themselves will also likely vary depending on organisational mission, cultural history, and the practices that are utilised to achieve its aims (see Macaulay et al 2018). For example, Teasdale's (2010) UK ethnographic study found different social capital or employment impacts associated with social enterprise mission and organisation. Whilst some social enterprises enabled individuals to realise some dimensions of social inclusion (e.g. participation, social interaction and political engagement - see Burchardt et al 2005) within the particular enterprise settings, these did not necessarily extend to their experiences beyond these settings, for example, through 
securing participants access to paid employment. Nonetheless, they still provided wellbeing facilitative experiences that participants may not have otherwise experienced. Enterprises which focused on economic outcomes were more successful at securing the production element of inclusion (e.g. employment), however, this was often at the expense of achieving some of the more social objectives, such as political engagement and belonging. Thus, Teasdale emphasises the need for caution and nuance when determining which particular outcomes are used to evidence impact.

Given that impacts and outcomes may vary, questions of what is considered to be of value, and for whom also need considering (Arvidson and Kara 2013). More importantly, by focusing primarily on impact or outcomes, the processes and practices through which these are realised are left underexplored. Within the field of social enterprise research, health geographers Muñoz et al (2015) have begun to address this gap, utilising 'spaces of wellbeing theory' (Fleuret and Atkinson, 2007) to make sense of how social enterprise as spaces may be experienced as wellbeing enhancing. In keeping with the health geography literature more broadly (Conradson, 2005), Muñoz et al's (2015) work shows spaces are not inherently wellbeing facilitative but highlights the importance of how individuals engage with and relate to space and their environment for wellbeing.

The productive spaces in which individuals participated in practices ('doing well being') were most strongly associated with wellbeing (Muñoz et al 2015). The value of occupation for wellbeing has been well-established in the occupational science literature (see Eakman et al's 2018 for a useful evidence synthesis on this matter). However, in relation to gardening in particular, much of this research has been conducted within therapeutic settings as opposed to social enterprises (Sempik et al, 2005; Parr, 2007; Diament and Waterhouse, 2010). Given that supportive sociocultural contexts are necessary for occupations to fulfil basic needs (Eakman et al 2018: 361), organisational purpose and form is also likely to influence how practices are utilised. Thus, it is possible that organisational context may also mediate the meaning which is derived from participating in practices. It is therefore fruitful to pay closer sociological attention to the practices social enterprises utilise to achieve their ends, for example how those who engage in these particular practices relate to these practices, and what 'goods' they seek to achieve through their participation in these practices. 
The data presented here were generated during an ESRC funded doctoral studentship, which explored the relationship between values and practices, at one site of a mental health education and training organisation, which utilised gardening as rehabilitative tool. Ethical approval was received from Cardiff University Ethics Committee.

\section{Theoretical Framework: Alisdair Maclntyre's practice-based approach to wellbeing} Maclntyre's (2007) theory is heavily influenced by the virtue-ethics of Aristotle. This approach contends that it is only through the acquirement of the virtues, that human beings are able to achieve wellbeing. These virtues are acquired through engagement in practices, and it is only through seeking excellence in practices that human beings are able to cultivate and acquire the qualities or virtues needed for them to live well and thus achieve the greatest good of all - happiness or eudaimonia ${ }^{1}$. For Aristotle, all human action must be understood teleologically, that is, in terms of the extent to which the particular ends of human action allow individuals to get closer to realising the chief good of eudaimonia. Well-being is well-doing, and well-doing means realising, in practice, a particular idea of the good (Aristotle, 2002).

However, Aristotle's virtue ethics is in some ways dated in terms of its usefulness for application. The virtues Aristotle identified were those which were necessary to live well in the Athenian city state. The neo-Aristotelianism of Alasdair Maclntyre (2007) offers a way to operationalise the theory in modern societies characterised by value-plurality. Rather than identifying the virtues as the qualities that are needed to live well within a city state which no longer exists, Maclntyre posits that the virtues can only be identified in relation to particular practices. Individuals cannot realise excellence within a practice without the cultivation and practice of the particular virtues or qualities which are necessary for them to achieve this. The 'internal goods' of a practice, therefore, are the particular skills, virtues, or qualities that are necessary for doing well or achieving excellence within a particular practice. Practices include:

Any coherent and complex form of socially established cooperative form of human activity through which goods internal to the form of activity are realised in the course 
of trying to achieve those standards of excellence which are appropriate to, and partially definitive of that form of activity, with the result that human powers to achieve excellence, and human conceptions of ends and goods are systematically extended (Maclntyre, 2007:187).

Examples of such practices could include chess, football, gardening, farming, painting and music. The sustenance of communities, families, cities and nations are also considered by Maclntyre to be practices through which internal goods are produced. Practices can also produce external goods, which are goods that are not specific to particular practices - for example, money, status and prestige. Thus, external goods can be obtained through a variety of practices, whereas internal goods can only be produced through particular practices, since the meaning of such goods can only be specified in relation to that particular practice.

However, practices cannot be sustained without the development of organisations, and this often hinges on the production of external goods. Therefore survival in a market driven environment may be necessary to develop the internal goods intrinsic to the practices they are sustaining. This can therefore produce a tension between the production of internal and external goods, since the 'ideals and creativity of a practice are always vulnerable to the acquisitiveness of an institution' (Maclntyre, 2007: 194). This tension receives little empirical exploration from Maclntyre (2007) as it is his contention that such communities of practice are rare in the modern liberal individual era where the notion of a common project, politically at least, seems an alien concept. This is precisely why there is no modern value consensus on how life should be led (Maclntyre, 2007).

This tension may have relevance in the case of social enterprises, especially for founders and practitioners for whom working for a certain organisation has appeal because of its individual mission and values. This creates an opportunity for values expression potentially favouring the production of internal goods over external goods. Indeed, Maclntyre's recognition of the tension between internal and external goods is perhaps evident in the commonly referred to difficulty in maintaining the balance between social and financial goals (Teasdale, 2012; Spear et al, 2009). Further, the fact social enterprises often work with those who are vulnerable, may also make them well placed to foster the pursuit of internal goods over external goods. 
From a Maclntyrean perspective, attempting to address the needs of those beyond your closest networks, would indicate evidence of the virtue of 'just generosity', that is, the exercise of uncalculated giving, which underpins the kind of communal relationships Maclntyre argues are needed for practices and communities to thrive (Maclntyre, 1999).

If this approach is taken to assess how well social enterprises foster wellbeing, then attention needs to be paid not just to the outcomes they may produce - something which itself is challenging given the difficulty evidencing causal mechanisms (Roy et al 2013). We must also attend to the healthiness of the practices they house, and the orientation towards these practices and communal relationships encouraged by so-called experts in these practices, such as social enterprise leaders. Rather than seeking for what can be generalizable (i.e. measurements and outcomes), this approach pays attention to the specifics of practices, since from a Maclntyrean perspective, qualities such as 'empowerment', 'relatedness' and 'capability' - all qualities or goods associated with social enterprises - can only be understood in relation to the practices they are accrued within.

\section{Methods}

\section{Case Study site - Lles}

The study was carried out over 18 months (May 2012 - December 2013) at Lles, a mental health training and employment organisation, which utilises the practice of gardening as rehabilitative tool. The organisation is situated within the grounds of historic gardens on the rural outskirts of a Welsh city. It is part of larger mental health organisation which aims fight mental health discrimination, and to help those with serious mental illness achieve a better quality of life. The organisation uses gardening as a tool to equip service users with practical, or 'pre-employment' skills, with the aim being for individuals to progress into education, training or employment within two years of using the service. Individuals attend Lles via a referral from their community psychiatric nurse (CPN), their psychiatrist, or their GP. Although the organisation does not pay service users for their time, it functions as a place of work, and broadly aims to re-integrate individuals back into a workplace, thus making it comparable with some of the empirical work on work integration social enterprises (WISEs) (Teasdale, 2010; Munoz et al, 2015). 
Initially there was no fixed site, with site leader and gardener, John, along with those who were referred to the service, providing a garden maintenance service for whoever would pay, putting any profits back into the organisation. In 1998 a site was acquired, along with threeyears of funding from the health board. However, Lles continued to engage in some enterprising activities, providing an outreach gardening service for carers, and selling produce such as hanging baskets at open sales events held throughout the year.

\section{Participants}

The study sample included four paid staff, comprising of two gardeners (a male and female), the site manager and the regional manager (male), two volunteers (female), and ten service users (seven male and three female), only two of whom were formally interviewed (both male). Service users were aged between 20 and 60, and all had enduring mental illness such as bi-polar disorder, schizophrenia or serious depression. Data are presented in this paper using pseudonyms, including the participants, the organisation and location.

\section{Participant observation - observer-as-participant}

Participant observation was used to understand the everyday practices of the case site and to observe how participants attributed value to these practices, and what 'goods' were considered worthy of pursuit. The researcher volunteered one day a week in exchange for access, with each visit lasting between 4 and 6 hours. Because of the researcher's role as participant, field notes were typed up following site visits. Initially, field notes were used to capture the everyday activities, informal conversations with participants, and, given the study's focus on values, anything which struck the researcher as interesting and pertinent to this issue. Early stages of immersion were used to inform reading and to develop a theoretical framework. Aristotelianism, and in particular, Maclntyre's internal and external goods theory were not settled on right away but were rather the result of an iterative process which involved thinking about the data generated in the field notes in relation to potentially relevant theory. The relevance of Maclntyre's internal and external goods theory became apparent in the tension that existed between employees and managers concerning the value which was accorded to the practice of gardening, and how this seemed to be about differing ideas concerning what constituted excellence in practices, and wellbeing. 


\section{In-depth semi-structured interviews}

Eight audio-recorded in-depth semi-structured interviews were conducted with managers (two), employees (two), volunteers (two) and service users (two). Interviews were conducted seven months after being in the field. This meant the researcher had a prior relationship with all participants. Rubin and Rubin (2005) suggest that conducting interviews with individuals with whom rapport and trust has already been built is more likely to generate meaningful data than interviews which occur in circumstances where the researcher meets the participant as a 'rootless stranger' (Rubin and Rubin, 2005:92). It also allowed time to develop the interview themes in line with emerging impressions garnered from informal interviews and observations in the field. The purpose of the interviews was to add depth to the more tacit understanding of participants' experiences, gained through participation, and to explore in more detail how participants related to the everyday practices of the organisation (Miles and Huberman, 1984).

\section{Analysis}

Fieldwork data and interview transcripts were analysed thematically (Braun and Clarke, 2006), with analysis occurring in tandem with data generation. Initial themes were largely data generated, and included codes such as 'inclusiveness', 'work', 'balance', 'learning by doing', as well as what were initially more broad and general themes relating to extracts about gardening and how participants understood the organisation's successes and limitations. Interpretations of the fieldwork data were also sense checked with participants during informal interviews and conversations, to ensure that interpretations were faithful to their own experiences and perspectives. The codes and themes developed were both inductive (codes and themes derived directly from the data) and deductive (codes and themes informed by the neo- Aristotelian theory of Alasdair Maclntyre) (see Layder, 1998). The analysis was informed by the principles of critical realism, which represents a middle ground between purely positivist and interpretivist epistemologies. In this approach theories both shape and are shaped by the empirical data which emerges from the research, with theory being used and/or generated to help understand the connection between structure and agency in the particular social context being researched. Thus, the analysis of a data within this framework is a process which gives importance to both subjective meaning and experience, but also seeks to understand this by considering 
the broader structural or systemic conditions in which these meanings and experiences are embedded (Bhaskar, 1979; Layder 1998).

\section{Findings}

How the practice of gardening was understood to facilitate wellbeing

\section{Gardening as meaningful work and occupation}

The link between gardening, nature and wellbeing has long been established with the research literature across multiple disciplines (Kaplan and Kaplan, 1989; Ulrich, 1979; 1982 cited in Maller et al, 2005; Gonzales et al, 2009; 2010). However, to assume that such wellbeing conducive qualities are somehow intrinsic to gardening or nature, is to underplay the fact that any health and wellbeing benefits are likely to be contingent on how individuals relate to particular practices. Service users and volunteers freely chose to attend Lles, with most attending a couple of times a week, and a few attending every day. Participants attended Lles because they enjoyed their time there and experienced gardening as being good for them in some way. Indeed, most service users had a passion for gardening and did not necessarily have gardens of their own.

However, for gardeners, John and Anne, it was not just gardening, but also the particular relationship to gardening and the organisation, they attempted to foster that was understood as being good for service users.

John and Anne were keen to create a structured working environment as this was viewed as important for achieving Lles's goal of getting people back into work:

It's more therapeutic for them to go to a bus stop, get on a bus, come here, do a day's work and then go back on the bus. That's like getting yourself motivated to go back to work isn't it, more than simply picking somebody up and dropping them off. (John)

John explicitly saw the role of Lles as providing an opportunity for 'a day's work', attributing therapeutic benefit to this. Individual agency was viewed as important for this process, since service users had to make their own way to the site. For John this was therapeutic, not only because it realistically mirrored work, but because the self-motivation it required was perceived as empowering for service users. Anne viewed the role of the organisation in a similar sense, explaining in the following extract how she fostered a working environment: 
I always set things up for the whole day... the last thing I want them to do is sit about, not because I'm a slave driver, but because I don't want them bored. So if people want to sit down for five that's fine, [but] I don't want them sitting in there until eleven in the morning. It's too long. What is the point in coming in somewhere and just sitting or standing about? (Anne)

John and Anne were also keen to have service users come to Lles as much as they could, believing that this 'helps change their mind-set' and 'results in them wanting to do a whole load of other things' (Anne). For Anne, developing the habit of working or doing something every day was understood as a catalyst for all aspects of the individual's life, helping them to move out of the 'rut' they had got into. Thus, the work ethic, and its association with the development of agency and responsibility, was understood by employees as being important for aiding the process of recovery from mental illness. Service users were therefore encouraged to relate to the garden as if it were a productive space, in line with the working day. For example, arriving late and/or leaving early was often discouraged - albeit mainly through humour.

Contributing to this productive space, was perceived as being good for their own wellbeing and the wellbeing of others, since tending and sustaining the garden, allowed others to enjoy and benefit from it, as the following quote from service user, Eric demonstrates:

I am still on benefits but I feel like I am earning my benefits by working up here. Obviously with the old place we were selling stuff and it would go back into the charity so obviously I was helping out in that way. I felt that it had some purpose to it. (Eric)

Nonetheless, whilst John and Anne perceived the purpose of Lles as being primarily about moving service users into work, for service user Eric, such a goal was perceived as unrealistic and undesirable:

A job would be out of the question for me if I am honest with you. It's just too stressful for me, if there's any slight stress I become ill. This is the only thing I've found really, is 
here, that's not stressful. So I can live an active life and have a certain quality of life too... The work I do here keeps me well. (Eric)

Thus, although servicer users Harriet and Gareth, and volunteer, Jane viewed their time at the garden as the means to accrue the skills necessary to move on to paid work involving horticulture, like Eric, for most service users the goal of employment was viewed as unrealistic. Further, although they perceived their time at Lles as work, gardening at Lles differed dramatically from their previous experiences of paid employment, and this difference concerned the inclusiveness of gardening as a practice.

\section{The practice of gardening as inclusive}

Firstly, gardening is seasonal, and one has to work with the rhythms of nature by being patient and waiting for things to grow. Because of this, time and its relationship to productive value is understood in relation to the particular season and hours of sun light in the day, rather than in terms of the number of hours on the clock, as in the case of the modern workplace. Whilst the seasons mean that the pace and volume of the work may vary at different times of the year, there is always work to be done and plants to be attended to. The work of tending and caring is also tolerant of different paces, since nature is highly robust and allows margins for error.

Secondly, the output of a gardener's labour is in part dependent on variables that one cannot entirely control, such as the weather and the presence of pests, which takes some of the responsibility away from the individual gardener for the overall fruits of their labour. In a commercial setting, these two aspects may at times be in tension with consumer demand for particular produce. However, given that the focus of effort was for the most part not consumer demand but on the broader 'wellbeing' ideals of Lles, it did not matter if individuals worked at different paces and with different rates of success, since the overall collective effort meant that something would usually come to fruition from the work. Because of this, there was no sense that anyone was ever letting the team down by not working fast enough, meaning that everyone could be included, regardless of energy level, motivation or skill.

For Eric, the difference in the pressure between commercial and wellbeing ideals could be inferred in his contrast of gardening activities with his job as a training officer where there 
was pressure on sales, and for Gareth in his contrast with the pressurised environment of being a chef:

That was more office based, target driven, goal orientated... here is totally the opposite. (Eric)

There's no pressure, there's not the pressure to get it perfect. You know you haven't got twenty people waiting and screaming at you to get the food out, like when I was cooking and that kind of stuff. (Gareth)

The limited commercial pressures, coupled with the fact that the site was meant to be a space which was specifically for the benefit of service users, also meant that it was an entirely non-competitive environment, as suggested in Eric's comparison above. This made the experience of teamwork a genuinely inclusive one, since the reward resulting from the work was enhanced by collective input and effort. For some participants the experience of camaraderie and teamwork contrasted to their experiences of work outside Lles. For example, for Eric, the experience of genuinely working in a team contrasted with his experience of employment, which was dominated by competition and pressures to make sales. For him, the absence of competition with colleagues was in part what made the environment 'stress free'. Similarly, for service users, Gareth and Harriet, the lack of stress at Lles contrasted with their experiences as chefs. For service users who were vulnerable and excluded from the workforce due to their mental illness, this space allowed them to be productive whilst protecting them from some of the potentially more exclusionary aspects of the mainstream workplace.

Although this mirrors some of the other work on WISEs, it was the perceived inclusiveness of gardening work, and how participants were encouraged to engage in this work which led to it being understood as being amenable to wellbeing:

I think the key word for me is inclusiveness, and everyone who is there is included I think.

It goes back to the fact that they see people first and foremost as people. They don't focus on the illness, and that's how it is to have mental illness in the family too. You 
don't see that person as an illness. You see that person as a person. (Sarah, volunteer)

This inclusive ethos was specifically credited to the characters of John and Anne, and their seeming ability to 'accept people as they are' because they made the focus 'not around care, but on what we do'. This shifted from a focus on illness and onto a focus on activity, thereby mitigating the potential stigma of having a mental illness. For Sarah, this personcentred focus enabled John and Anne to 'get the best out of people', despite them being 'seriously ill' during their time at Lles. It also related to the fact that they were easily able to tailor the work to fit those with different abilities, encouraging service users to work in ways which suited their needs. Service user Gareth appreciated this quality:

What I like about coming here... it's very much, go at your own pace, do what you can, if you can't do it, you let them know and it's fine... I can push myself and I can work as fast as I can, or as hard as I can, and go home exhausted but happy. (Gareth)

Gareth enjoyed engaging in some of the heavier work. However, his ongoing problems with sciatica also meant that he was sometimes unable to engage in the heavier work or come to Lles at all. The variety of tasks available therefore allowed him to choose the work that best suited his physical health. This was apparent with all service users, with John and Anne usually setting up a number of tasks for the day and then allocating them in terms of what different service users enjoyed or were able to do on that particular day.

Whilst it was clear that participants understood their engagement in everyday practice of gardening as wellbeing enhancing, it is important to note that the organisation was relatively unsuccessful at moving services users on into work or voluntary opportunities, although success stories were still predominantly framed in this way. This created a source of tension between garden employees and the manager, Dan. According to Dan, Lles was failing to secure the wellbeing of service users. For example, Dan believed that individuals attending each day were not exercising agency but rather were demonstrating dependency: 
It's very much a dated model [...] of 'come to us, we'll put our arms around you, you won't have to worry about anything, we'll take care of everything' - and that's not how life is. (Dan)

In his view, Lles 'institutionalised' people, and thus failed to enhance social inclusion and wellbeing. Consequently, he believed that the practices needed to be changed in such a way as to move people on more effectively (whether this was into work or not). To do this, he had proposed that John and Anne deliver a horticultural qualification as this would provide a tangible outcome. A qualification would also act as a potential means to more readily move service users on, for example by enhancing the employability of participants, therefore fostering more short-term engagement with the organisation and preventing institutionalisation. In contrast to Dan however, John and Anne understood Lles as being both enabling and inclusive regardless of whether it resulted in a move on, since the value of moving on was something that could only be determined by the individual in question.

Indeed, moving service users on before they were ready was viewed as undesirable and almost cruel:

When people first come, they either are coming because they want to get better, because they want to move on; or they're coming with a totally different attitude. They're not coping with life very well and this is a safe environment... And hopefully they will gradually get confident. But they're not necessarily wanting to move on. They're not necessarily wanting to move into work, or voluntary, or anything. Some people are just trying to get their head together... I think that's the most important thing for people really - rather than trying to push people out before they're ready. If people are ready, that's great. That's fantastic isn't it?! If they're not ready - if they're still struggling with their head - then I think it's the pits to try and push them out into something. (Anne)

For Anne, instilling the confidence and resilience necessary to move on, took time and rested on service users' continued engagement in the practices of the organisation. Indicative of this, was how John and Anne attributed the change in 'mind-set' to service users attending every day. However, the everyday attendance necessary for a change 
in mind-set to occur was difficult to achieve because the unstable nature of some service users' mental health meant that attendance fluctuated. Thus, achieving a change of mindset was not a linear, progressive process. For example, Mike - a service user with schizophrenia - displayed fluctuating levels of confidence when it came to taking responsibility for the carpentry work at Lles. When he was feeling well, he seemed more confident and took on more responsibility, but when he had just been discharged from hospital it always took him a while to build up his confidence. This would continue for a few months, but then he would find himself set back again following another psychotic episode.

Given that these sorts of patterns were common, it was important for John and Anne that Lles also existed as a space where service users could 'get their head[s] together'. Because of this, both attributed a huge amount of value to the day-to-day positive benefits for service users, as suggested in the following:

I like to see when people come in the morning, they're a little bit down because they haven't been here, but after they have been here an hour or so you can see the difference in them. Their morale has gone up a little bit and I get a pat on the back seeing that happening all the time. (John)

Through being attentive to the needs of each service user, John and Anne were able to accrue positive benefits from their work even if this did not necessarily lead to the desired outcome of moving people on. For them, the value of their work was specifically connected to realising the wellbeing of service users, whether this be on a day-to-day level or in a more profound way. The latter was concerned with how they tried to use their work to realise capabilities. For both John, Anne, and volunteer Jane, there was an explicit link between gardening, and what Sen (1985) and Nussbaum (2000) refer to as the realisation of capabilities, as this quote from Jane suggests:

I like the idea of growing things being a sort of, not just a social activity, but a way of doing good to the people involved.... I think I like and get a buzz from the idea of gardening being used as an aid, not just for adults with mental health issues. I like the idea of it enabling people who are perhaps elderly. (Jane, volunteer) 
At Lles, it was the realisation of capabilities which enabled service users to garden well. For Anne, working with service users in this way was perceived to have an almost transformative impact, and this was where the real value of her work lay:

They haven't got time to think about how they're feeling, that they're not feeling okay; because they're trying to do whatever it is I am getting them to do. And they go home a different person and I love that, I love that. (Anne)

For Anne, it was explicitly what she got service users to do which had impact. The transformative effect perceived by Anne, not only arose out of mastering the use of a particular tool, but more importantly out of how this skill enabled service users to become better gardeners. Part of the way in which John and Anne did this was by making use of the skills some service users already had. Gareth in particular seemed to value the opportunity to engage in something he felt naturally played to his strengths:

Being dyspraxic, most gardening spec and most outdoor work... doesn't have to be as neat and as perfect... I can be creative; and I won't say artistic, but I can express what creativity I do have better on a larger scale than by drawing or painting, because I can't draw and paint. (Gareth)

This was also important for John and Anne, since it focused on individual capability, rather than on recovering from a particular illness (implying deficiency). To be good at this depended on John and Anne being attentive to each individual's history. For example, service user Mike was encouraged to take responsibility for the carpentry as this was what he did before he became too ill to work. When he was feeling confident and well, he took pride in his skills and enjoyed teaching others. However, not all service users had a history which involved using the skills needed for the day-to-day practices at Lles, so this meant providing opportunities for service users to try new things in order to find out what they were good at, and then encouraging service users and volunteers to relate to these practices in a particular way. The latter concerned encouraging the seeking of excellence within practices, since in their view, doing well contributed to being well. Whilst the managers did not view becoming a good gardener as a valuable outcome, for employees, it was the process of becoming good at something, and feeling capable and competent in a 
practice which was perceived to provide people with a sense of pride, self-worth and resilience in the face of adversity. Anne reflected on this during her account of how she ended up leaving her career in commercial gardening to pursue a career at Lles:

When I was pregnant we moved over to Wales and we bought a derelict house, and I didn't know that men couldn't do things. I thought all men could do things, but they can't I found out. Geoff can't, and didn't want to anyway. So I found that I could do things, and we lived on a shoestring. We had no money and yet, we were doing up this thing, and we done it, and I did the garden and I learnt to plaster and I put windows in. I thought, 'do you know what, I am a worthwhile person and I don't care if I get the job or not, because I know I am a worthwhile person. (Anne)

For employees being able to practice gardening in a way which was conducive to seeking the internal goods of this practice, was therefore viewed as important for facilitating wellbeing, since it was only through doing this that service users were able to acquire the skills, habits and qualities necessary to achieve wellbeing. For managers however, gardening was only perceived as vehicle to achieve particular organisational outcomes, therefore how service users were encouraged to relate to this practice was largely unimportant. Indeed, for them, the commitment John and Anne sought to foster was counterproductive to Lles's wider goal of reintegrating service users back into wider society, since this commitment effectively institutionalised service users, and thus harmed their wellbeing:

We're not running [this] for people to come here all their lives... If you had the NHS day centre and they had people coming there 15 years, they would get criticised for it... People would say... that you've institutionalised these people, but we've done exactly the same with some of our clients... You can't keep people on your books. You have to have an outcome (Dan, manager)

The tension with respect to how the organisation should utilise the practice of gardening concerned the different value which was accorded to different 'goods' Lles created, and differing views with respect to what constituted wellbeing. The following demonstrates the difference between the internal and external goods of the organisation, and some of the 
possible implications for wellbeing which may have arisen had Lles shifted the balance of goods it pursued.

The internal and external goods of gardening

As mentioned above, Dan, the manager understood the organisation's value predominantly in relation to its capacity to produce external outcomes - what would be understood in a Maclntyrean sense as the 'external goods' of practices, or goods of effectiveness. These included move-on outcomes, such as work, or the gaining of a qualification, and the goods of status, prestige, which were associated with such outcomes. These goods were important in that they were essential for sustaining the funding that enabled Lles to continue its practices.

However, because managers predominantly understood the value of internal goods in relation to Lles 's ability to achieve external goods, they tended to overlook the importance of the 'internal' goods for the generation of service users' wellbeing. As previously touched upon, the introduction of a qualification was perceived as a way to better demonstrate impact to their funders:

We're moving more towards contracts stipulating that there are certain outcomes we must have. If the contract says you need 30 people to get $x$ qualification - if you don't-you've failed. (Dave, area manager)

Interestingly, it was also viewed as a way of producing 'hard' evidence of some of the softer wellbeing outcomes Lles already facilitated.

[With] a level 1 gardening qualification you get evidence - brilliant - of an educational qualification. But what you're not evidencing there is the link with increased self-esteem that comes from doing that. The increased communication skills that may have come from doing that. The team work skills from taking part in group sessions to achieve the qualification, so all those different things that are harder for us to pin down. (Dave, area manager)

However, only two service users were interested in obtaining a qualification, so the managers were unable to initiate this change. Nonetheless, this example importantly illustrates the difference in the balance of 'goods' which would be achieved if Lles delivered 
a qualification. Teaching the qualification would have entailed Anne doing a large part of it indoors, on a computer (online plant identification). This aspect of gaining the qualification would fit with the nature of 'soft skills' in the context of the average workplace.

For example, being able to demonstrate a capacity to use the internet as a basic search tool, would be useful for a number of things such as accessing other services, and applying for jobs. However, this went against the hands-on style of learning encouraged by John and Anne and would also involve less gardening. Further, for Anne, not only did this go against the logic of gardening, but it was also ineffective, as service users would be more likely to forget knowledge learnt from a book or at a desk. This was because for her it was the more embodied form of knowledge, only developed and implemented through practice that enabled one to remember, and to get better at this practice. Further, this 'good' was also not deemed worthwhile by service users and volunteers who came to Lles of their own accord because they enjoyed doing so, and did so on terms that suited their own interests and capacities.

Whilst John and Anne also viewed outcomes such as moving on or gaining qualifications as important indicators that Lles had achieved its goal of facilitating the recovery and wellbeing of service users, this was only if these outcomes were understood as meaningful and important for the individual in question. Prioritising the achievement of external goods over internal ones, was therefore understood to undermine their ability to realise wellbeing, since applying this rule without paying to specific capacities and vulnerabilities, would be at odds with the whole-person approach they adopted. Further, whilst gaining a qualification would involve a number of important functionings (Sen, 1985) such as being able to read and use the internet - which taken together can act to enhance capability - capability is only realised if there are meaningful opportunities available to exercise these various functionings, and opportunities beyond Lles were limited for some service users, particularly those who were older, such as Eric. Employees were well aware of this, so for them, the fact that Lles could provide a space which enabled service users to achieve some kind of quality of life was of value of itself.

For employees, volunteers and service users, Lles's capacity to facilitate wellbeing resided in the internal practices of the organisation, and the achievement of the 'internal goods' of these practices. These were those skills, habits and virtues which were needed to cultivate 
and care for plants flowers for the full growing cycle (from seed to adult plant). For example, knowledge of how to propagate seeds, how to make good compost, and when and where to plant particular plants and flowers for them to flourish, and then how to care for them, were all internal goods. Achieving these goods also rested on learning to use the right tools in the correct way. Thus, things like being able to weed properly, or being able to build raised beds and greenhouses - the sorts of skills the managers' felt were superfluous to the world of work beyond Lles - were internal goods here. They all constituted part of what it was to garden well, and it was only by gardening well that others could share and benefit from the 'goods' of this community.

These goods were sought out by participants because they all had a genuine interest in the practice of gardening. The virtues which were cultivated at Lles were also goods internal to this community (i.e. commitment, industriousness, patience, and care). For example, commitment, patience and care had to be exercised in every part of the growing process in order to achieve the internal goods of gardening. These virtues were drawn on to achieve not only the internal goods of gardening, but also the 'good' of wellbeing in this setting. Therefore, the confidence and skills gained, were not abstract, transferable qualities, but rather in the Maclntyrean sense, were qualities rooted in the practices, and the social recognition of doing well in this particular community. This is important for understanding the power of social enterprises to 'fix' particular social problems, if outcomes are used as the only measures of wellbeing, then the value of practices as ends in themselves is overlooked.

\section{Discussion and conclusion}

Although the findings presented above are limited in their generalisability, they nonetheless provide some interesting insights into how social enterprises may facilitate wellbeing. The organisation offered vulnerable individuals the opportunity to participate in particular practice-based community whereby individuals were encouraged to do well in their practices, with service users and volunteers, gaining a sense of recognition, purpose and belonging through their contribution to the ongoing sustenance of this particular mental health community, evidencing what has been identified elsewhere in the research literature on WISEs (Teasdale, 2010; Muñoz et al 2015; Macaulay et al 2018). In support of Muñoz et al (2015), it also shows that these wellbeing effects were contingent on the relationships 
which were developed in this particular setting, thus it cautions against generalising, and instead suggests greater attention be paid to the specifics of organisations.

Whilst this research demonstrated that being able to participate in the practice of gardening was of value for participants irrespective of the wider outcomes which were generated, it is limited by the fact that it did not explore whether the skills, habits and qualities, they acquired enabled participants to live well beyond the study site. It is likely that impact was somewhat limited in this sense. For example, service users' participation in the daily practices of the organisation did not 'fix' their enduring, long-term mental health conditions, nor did it tackle the poverty which is known to underpin poor health and wellbeing outcomes (Wilkinson and Marmot, 2003; Marmot et al, 2008). To expect social enterprises to be a panacea for these so-called 'wicked problems' is perhaps unrealistic, but this does not mean that the work that they do is not of value for wellbeing. Indeed, it is important to note that opportunities to participate in practices outside the organisation in this more Maclntyrean- sense were perhaps limited. This is not only because those with mental health conditions are excluded and discriminated against in wider society, but also because the dominance of the market, which favours the achievement of goods of effectiveness over goods of excellence.

In this sense, social enterprises, with their balance of social goals and economic goals, allow for the achievement of a plurality of goods (Peredo and McLean 2006) - and consequently can foster both goods of effectiveness and goods of excellence, and this balance makes them well placed to provide opportunities for vulnerable individuals to participate in practices in a way which is facilitative of wellbeing. However, their success in doing so is often contingent on the personal narratives and stories which inform their work, and the commitment and skills of leaders to be able to combine and balance the plurality of goods they seek to create (Pearce, 2003). At Lles, it was John and Anne's 'virtue of character' and their attention to individuals' strengths that enabled them to utilise practices in a way which facilitated the wellbeing of service users.

For Maclntyre (1999) it is only through our communal relationships of giving and receiving, that the virtues can be acquired and sustained. This is because it is only through recognising the goods of a community, that an individual can determine his or her own good (Maclntyre 1999: 109). In this sense, John and Anne acted as mentors inculcating the skills, habits and 
virtues to enable service users to thrive in this community. This is important with respect to social enterprise, since Maclntyre contends that neither the family nor the modern state are likely to provide the kind of communal relationships which are needed to achieve the type of common good through which our own good can also be realised. Social enterprises are more likely to embody the type of communal association conducive to achievement of the common good. This is because they are likely to exemplify the three conditions Maclntyre argues are needed for those relationships of giving and receiving to thrive. These include shared political decision-making, the exercise of the aforementioned virtue of just generosity, and political structures that give a role for those who are more vulnerable in communal deliberation about what the norms of justice require (Maclntyre, 1999). Maclnytrean theory, with its focus on, goods pluralities, practice-based communities, and communal relationships, provides a useful lens to explore social enterprise and wellbeing.

It is also compatible with other assets-based approaches, such as capabilities theories (Sen, 1999; Nussbaum 2000), which already have a well-established evidence bases as theories of wellbeing. However, unlike these approaches, it also offers a means to objectively assess particular social phenomena in a way which is historically and culturally sensitive through its focus on social practices. It therefore takes account of a plurality of goods and provides a way to move beyond the universalism of capabilities approaches. Operationalising this approach, however, is time consuming and necessitates becoming familiar with the practices under study and its experts in order to understand how participants relate to these practices, and what 'goods' they seek through their participation. Nonetheless, with this theory of wellbeing it is possible to assess which 'goods' are pursued by social enterprises, the health of the practices they house, and thus the capacity of these practices to facilitate the wellbeing of those who participate in them. 


\section{References}

Aristotle, (2002) Nicomachean Ethics translation, introduction and commentary by Sarah Broadie and Christopher Rowe. Oxford: Oxford University Press

Arvidson, M. and Kara, H. (2013) Putting evaluations to use: from measuring to endorsing social value Third Sector Research Centre Working Paper 110 Birmingham: TSRC

Bashkar, R. (1979) The Possibility of Naturalism Brighton: Harvester

Bertotti, M., Harden, A., Renton, A., Sheridan, K., (2012). 'The contribution of a social enterprise to the building of social capital in a disadvantaged urban area of London'. Community Development Journal. 47 (2): 168 -183.

Braun, V. and Clarke, V. (2006) 'Using thematic analysis in psychology' in Qualitative Research in Psychology 3 (2): 77-101

Burchardt, T., Le Grand, J. and Piachaud, D. (2002) ‘Degrees of Exclusion: Developing a Dynamic, Multidimensional Measure', in Hills, J., Le Grand, J. and Piachaud, D. (eds) Understanding Social Exclusion Oxford: Oxford University Press pp 30-43.

Cabinet Office (2010) Modernising Commissioning: Increasing the Role of Charities, Social Enterprises, Mutuals and Cooperatives in Public Service Delivery London: HMSO

Conradson, D. (2005) Landscape, care and the relational self: therapeutic encounters in rural England. Health and Place 11 (4): 337-348

Department of Health (2006) No excuses. Embrace partnership now. Step towards change! Report of the Third Sector Commissioning Task Force London: Department of Health Department of Health. (2010) Social Enterprise in the NHS.

Defourney, J. and Nyssens, M. (2006) 'Defining social enterprise', in Nyssens, M. (ed.) Social Enterprise: At the crossroads of market, public policies and civil society, Abingdon, UK: Routledge

Department of Trade and Industry. (2002) Social Enterprise: A Strategy for Success. London: DTI 
Diament, E, and Waterhouse, A. (2010) 'Gardening and belonging: reflections on how social and therapeutic horticulture may facilitate health, wellbeing and inclusion' in British Journal of Occupational Therapy, 73(2): 84-88

Ferguson, K,M. and Islam, N. (2008) Conceptualising Outcomes with Street-Living Young Adults: Grounded Theory Approach to Evaluating the Social Enterprise Intervention. Qualitative Social Work 7 (2): 217 -237

Gonzalez, M. T., Hartig, T., Patil, G. G., Martinsen, E. W., and Kirkevold, M. (2009) 'Therapeutic horticulture in clinical depression: A prospective study.' Research and Theory for Nursing Practice 23 (4): 312-328

Gonzalez, M. T., Hartig, T., Patil, G. G., Martinsen, E. W., and Kirkevold, M. (2010) 'Therapeutic horticulture in clinical depression: A prospective study of active components.' Journal of Advanced Nursing 66 (9): 2002-2013

Fleuret, S., Atkinson, S., (2007). Wellbeing health and geography, A critical review and research agenda, New Zealand Geographer, 63 (2): 106-118

Haugh, H. and Kitson, M. (2007) 'The Third Way and the third sector: New Labour's economic policy and the social economy.' Cambridge Journal of Economics, 31 (6): 973-994. Ho, AP-y., Chan, K-t., (2010), 'The social impact of work-integration social enterprise in Hong Kong'. International Social Work, 53 (1): 33-45

Kaplan, R. and Kaplan, S. (1989) The Experience of Nature: A Psychological Perspective Cambridge, New York: Cambridge University Press Layder, R. (1998) Sociological Practice: Linking Theory and Social Research London: Sage Publication

Macaulay, B., Mazzei, M., Roy, M.J., Teasdale, S. and Donaldson, C. (2018) ‘Differentiating the effect of social enterprise activities on health'. Social Science and Medicine 220: 211-217 Macmillan, R. (2013) 'Distinction' in the third sector' in Voluntary Sector Review 4 (1): 39-54 Maclntyre, A. (2007) After Virtue (3rd edition) London: Duckworth Maclntyre, A. (1999) Dependent Rational Animals London: Duckworth 
Maller, C., Townsend, M., Pryor, A., Brown, P., and St Leger, L. (2006) 'Healthy nature health people: 'contact with nature' as an upstream health promotion intervention for populations' Health Promotion International 21(1): 45-51

Marmot, M.G., Friel, S., Bell, R., Houweling, T.A., Taylor, S., (2008). Closing the gap in a generation: health equity through action on the social determinants of health. Lancet 372 (9650): 1661-1669.

Miles, M, B. and Huberman, A, M. (1984) Qualitative data analysis. Beverly Hills, CA: Sage. Muñoz, S.-A., Farmer, J., Winterton, R., Barraket, J., (2015). 'The social enterprise as a space of wellbeing: an exploratory case study'. Social Enterprise Journal 11, 281-302

Nussbaum, M. (2000) Women and Human Development: The Capabilities Approach Cambridge: Cambridge University Press

Office for the Third Sector (2006) Partnership in Public Services: An Action Plan for Third Sector Involvement London: OTS

Parr, H. (2007) 'Mental health, nature work, and social inclusion' in Environment and Planning D: Society and Space 25 (3): 537-561

Pearce, J., 2003. Social Enterprise in Anytown. Calouste Gulbenkian Foundation, London. Peredo, A.M., McLean, M., (2006) 'Social entrepreneurship: a critical review of the concept'. Journal World Business. 41 (1), 56-65.

Roy, M., Donaldson, C., Barker, R., Kay, A., (2013), 'Social Enterprise: New Pathways to Health and Wellbeing?' Journal of Public Health Policy, 34 (1): 55 - 68

Roy, M., Donaldson, C., Baker, R., Kerr, S., (2014a), 'The potential of social enterprise to enhance health and well-being: a model and systematic review', Social Science and Medicine Roy, M. J., McHugh, N., \& Hill O'Connor, C. (2014b). Social Innovation: Worklessness, Welfare and Well-being. Social Policy and Society, 13 (3): 457-467

Rubin, H. and Rubin, I. (2005) Qualitative Interviewing: the art of hearing data (2 ${ }^{\text {nd }}$ edition) London: Sage Publications 
Sempik, J., Aldridge, J. and Becker, S. (2005) Health, Well-being and Social Inclusion, Therapeutic Horticulture in the UK Bristol: The Policy Press

Sen, A. (1985) Commodities and Capabilities Amsterdam: North Holland

Social Enterprise Unit (SEU) (2006) Social enterprise action plan. London: SEU, Department for Trade and Industry

Social Exclusion Unit (2004) Mental Health and Social Exclusion: Social Exclusion Unit Report London: Office of the Deputy Prime Minister

Spear, R., Cornforth, C., and Aiken, M, (2009). The governance challenges of social enterprises: evidence from a UK empirical study. Annals of Public and Cooperative Economics, 80(2) pp. 247-273.

Teasdale, S. (2010) 'How Can Social Enterprise Address Disadvantage? Evidence from an Inner City Community' in Journal of Nonprofit \& Public Sector Marketing, 22 (2): 89-107.

Teasdale, S., (2012). Negotiating tensions: how do social enterprises in the homelessness field balance social and commercial considerations? Housing Studies 27 (4), 514- 532.

Williams, A., Fossey, E., Harvey, C., (2010) 'Sustaining employment in a social firm: use of the work environment impact scale V2.0 to explore views of employees with psychiatric disabilities'. British Journal Occupational Therapy. 73 (11): 531-539

Wilkinson, R.G and Marmot, M.G (eds) (2003) Social Determinants of Health: the Solid Facts, $2^{\text {nd }}$ Edition. World Health Organisation. Regional Office for Europe, Copenhagen

\footnotetext{
${ }^{1}$ [the Greek word adopted in the work of Aristotle, commonly translated as 'happiness', 'welfare' or 'flourishing']
} 